\title{
Grupo de Estudos em Informática na Educação - GEInfoEdu
}

\author{
Amanda Meincke Melo ${ }^{1}$, Eliane Costa da Silva ${ }^{2}$, Jader de Freitas Saldanha ${ }^{1}$, \\ Maria Cristina Graeff Wernz ${ }^{1}$, Onório Isaias de Moura ${ }^{1}$, Rogéria Guttier ${ }^{1}$ \\ ${ }^{1}$ Universidade Federal do Pampa (UNIPAMPA) - Campus Alegrete \\ Av. Tiarajú, 810 - Ibirapuitã - 97.546-550 - Alegrete - RS - Brasil \\ ${ }^{2}$ Secretaria Municipal de Educação e Cultura de Alegrete \\ Major João Cezimbra Jaques, 200 - Assumpção - 97.543-390 - RS - Brasil \\ amanda.melo@unipampa.edu.br, anecostaarte@gmail.com, \\ saldanha.jader@unipampa.edu.br, maria.wernzeunipampa.edu.br, \\ onoriodemuraegmail.com, rogeria.guttier@unipampa.edu.br
}

O Grupo de Estudos em Informática na Educação (GEInfoEdu) do Campus Alegrete da UNIPAMPA, desde o início de 2010, desenvolve suas ações com os seguintes objetivos: constituir grupo de estudos na área de Informática na Educação visando à compreensão do contexto de uso de recursos de informática na educação, nos vários níveis (ex.: fundamental, médio, superior) e modalidades de ensino (ex.: presencial, a distância); desenvolver projetos de ensino, pesquisa e/ou extensão articulados ao cotidiano escolar/universitário. Participam de seus projetos e de suas ações docentes, discentes e técnicos administrativos em educação da UNIPAMPA, além de colaboradores externos - professores da Educação Básica das redes municipal e estadual.

O grupo já teve projetos de extensão contemplados com fomento externo em editais como PROEXT2010 - MEC/SESu, PROEXT2011 - MEC/SESu e Programa Novos Talentos - DEB/CAPES, com ações voltadas à formação de professores e de estudantes da Educação Básica para o uso das tecnologias digitais, além da promoção da inclusão educacional com apoio de recursos da informática. Neste contexto, acadêmicos da área da Computação têm desenvolvido trabalhos de conclusão de curso na linha de pesquisa "Acessibilidade e Inclusão Digital", recentemente vinculada ao Grupo de Pesquisa Tecnologia em Contexto Social (TESA). Esses projetos e trabalhos dialogam com atividades de ensino realizadas no Campus, sejam em disciplinas de graduação, sejam em projetos de ensino.

Atualmente estão em execução o projeto de ensino "Biblioteca - espaço significativo para o aprendizado e a prática da acessibilidade universal" (PBDA UNIPAMPA), o projeto de extensão "info.edu: Novos Talentos no Pampa" (Programa Novos Talentos - DEB/CAPES) e o projeto de pesquisa "Desenho Universal e Ambientes Educacionais Mediados pela Web" - os dois últimos em parceria com a Coordenadoria de Educação a Distância da Universidade.

Deste modo, o grupo tem contribuído à formação de profissionais mais reflexivos e conscientes sobre o papel social da Universidade e sobre seu próprio papel como cidadãos, assim como à promoção dos recursos da informática como importantes aliados na constituição de ambientes sociais inclusivos. 